\title{
Perencanaan ruang terbuka publik di Desa Dasan Cermen, Kota Mataram untuk mendukung aktivitas budaya lokal
}

\author{
Mita Putri Fitrasari ${ }^{1}$, Anak Agung Gede Sugianthara ${ }^{1 \star}$, Lury Sevita Yusiana ${ }^{1}$
}

1. Program Studi Arsitektur Pertamanan, Fakultas Pertanian, Universitas Udayana, Indonesia 80114

*E-mail: sugianthara@unud.ac.id

\begin{abstract}
Planning of public open space in Dasan Cermen Park, Mataram City to support local cultural activities. Mataram city has experienced development rapidly that causes the need of builded space is increased so that the quality of the environment is getting lower, so it needs the existence of public open space. In addition to having ecological functions, the existence of public open space also has a socio-cultural function as a place of social interaction and describes the local cultural expression. Based on these problems, it is necessary to have a public open space planning in the form of a park that can describe the local cultural expression. The purpose of this research is to plan the park in accordance with the local cultural identity of Mataram city. This research used survey method with observation technique, interview, questionnaire distribution and literature study. Planning refers to systematic planning method. The concept applied is the preservation of local culture. The final result of this research is planning of public open space in Dasan Cermen Mataram City which is divided into three spaces, such as conservation space, social space and cultural space. Further research is needed to design of public open space in Dasan Cermen Mataram City and attention to aspects of public open space management.
\end{abstract}

Keywords: culture, landscape planning, public open space

\section{Pendahuluan}

Kota merupakan perwujudan aktivitas manusia yang berfungsi sebagai pusat kegiatan yang menyebabkan kebutuhan ruang meningkat untuk mengakomodasi kegiatan sehingga keberadaan ruang terbuka publik (RTP) semakin terancam. Sesuai data Badan Pusat Statistik Kota Mataram (BPS, 2017), Kota Mataram mengalami peningkatan ruang terbangun yang cukup signifikan dari tahun 2008 hingga tahun 2016 yakni mencapai $4,9 \%$.

Pada dasarnya, RTP memiliki banyak fungsi baik secara ekologi maupun sosial budaya. Fungsi ekologi dari RTP dapat berupa ruang terbuka hijau (RTH), menurut UU Nomor 26 Tahun 2007 RTH adalah jalur dan/atau mengelompok, yang penggunaannya lebih bersifat terbuka sebagai tempat tumbuh tanaman, baik tumbuh secara alami ataupun sengaja ditanam. Fungsi sosial budaya RTP yaitu masyarakat dapat berinteraksi seperti tempat rekreasi, sarana olahraga dan menggambarkan kondisi dan budaya masyarakat. Kota Mataram memiliki beragam budaya mulai dari aktivitas sehari-hari/adat istiadat pada RTP dan kegiatan permainan tradisional (peresean dan begasingan) yang dapat dilakukan di RTP.

Oleh karena itu, dibutuhkan RTP untuk pelestarian lingkungan dan pelestarian kebudayaan daerah sekaligus memperkenalkan adat istiadat masyarakat Lombok. Perencanaan RTP berupa taman di Dasan Cermen juga untuk menambah persentase RTH Kota Mataram. Penelitian ini bertujuan untuk merencanakan taman sesuai dengan kebutuhan rekreasi masyarakat dan pelestarian budaya.

\section{Metode}

\subsection{Tempat dan Waktu Penelitian}

Penelitian ini dilakukan di Kelurahan Dasan Cermen, Kecamatan Cakranegara, Kota Mataram, Provinsi Nusa Tenggara Barat. Penelitian berlangsung selama delapan bulan yakni dari bulan November 2016 sampai dengan Juli 2017. 


\subsection{Alat dan Bahan Penelitian}

Alat yang digunakan dalam penelitian meliputi kamera sebagai alat dokumentasi, alat tulis, kuesioner dan perangkat lunak untuk mengolah data dan gambar. Bahan yang digunakan dalam penelitian adalah peta wilayah dan tapak Dasan Cermen.

\subsection{Metode Penelitian}

Metode penelitian yang digunakan dalam penelitian ini adalah metode survei dengan teknik observasi, wawancara, penyebaran kuesioner dan studi pustaka.

\subsection{Data Penelitian}

\subsubsection{Jenis Data}

Jenis data yang diperlukan dalam penelitian adalah data primer dan sekunder. Data primer diperoleh dengan observasi ke obyek penelitian serta melakukan wawancara dan memberikan kuesioner kepada responden. Data sekunder diperoleh dengan mencari berbagai sumber seperti hasil penelitian, buku, media internet dan dokumen ilmiah dari instansi terkait.

\subsubsection{Teknik Pengumpulan Data}

Penelitian ini memiliki data yang dikumpulkan melalui beberapa cara sebagai berikut:

1. Observasi tapak yaitu dilakukan pengamatan secara langsung pada kondisi tapak untuk mengetahui kondisi fisik tapak.

2. Wawancara yaitu dilakukan dengan tanya jawab langsung kepada informan. Informasi tersebut diperoleh dari Budayawan.

3. Kuesioner yaitu dilakukan dengan memberikan pertanyaan kepada 30 responden untuk dijawab dalam hal ini sasarannya adalah masyarakat lokal Kota Mataram yang berkunjung ke Taman Udayana, Taman Selagalas dan Taman Loang Baloq.

4. Studi Pustaka yaitu diperoleh dari hasil penelitian, buku, dokumen ilmiah, peraturan, ketetapan dan media internet.

\subsection{Batasan Studi}

Lokasi penelitian dilakukan di Dasan Cermen, Kecamatan Cakranegara, Kota Mataram. Perencanaan diharapkan dapat menjadi rekomendasi perencanaan RTP Kota Mataram bagi pemerintahan setempat.

\section{Hasil dan Pembahasan}

\subsection{Inventarisasi}

Tahap inventarisasi merupakan tahap pengumpulan data yang diperlukan dalam penelitian, meliputi data biofisik dan sosial.

\subsubsection{Aspek Biofisik}

1. Letak dan luas Lahan

Penelitian ini terletak di Kelurahan Dasan Cermen, Kecamatan Cakranegara, Kota Mataram seluas 8,6 ha dengan kepemilikan lahan oleh Pemerintah Daerah Kota Mataram. Lahan ini diperuntukkan sebagai ruang terbuka hijau dan berada di daerah pemukiman padat penduduk (Pemerintah Kota Mataram, 2011).

\section{Topografi}

Berdasarkan letaknya, Dasan Cermen berada di ketinggian 0-27m dpl yang merupakan daerah topografi datar sehingga memudahkan mengolah tapak (BPS Kecamatan Cakranegara, 2016).

\section{Kondisi Tanah}

Berdasarkan data BPS Provinsi NTB Tahun 2015, Kelurahan Dasan Cermen memiliki jenis tanah aluvial karena berada di tepi Sungai Unus. Tanah aluvial merupakan jenis tanah endapan dari lumpur dan pasir halus yang mengalami erosi tanah. Tanah ini memiliki tingkat kesuburan sedang hingga tinggi yang baik untuk pertumbuhan vegetasi. 
4. Iklim

Berdasarkan data BPS Provinsi NTB Tahun 2015, data iklim Kota Mataram 2015 dapat dilihat dalam Tabel 1.

Tabel 1. Uraian Iklim Kota Mataram Tahun 2015

\begin{tabular}{ll}
\hline Uraian Iklim & Nilai \\
\hline Suhu maksimum & $33,90^{\circ} \mathrm{C}$ \\
Suhu minimum & $19,90^{\circ} \mathrm{C}$ \\
Suhu rata-rata & $32^{\circ} \mathrm{C}$ \\
Kelembaban udara maksimum & $95 \%$ \\
Kelembaban udara minimum & $74 \%$ \\
Kelembaban udara rata-rata & $78 \%$ \\
Tekanan udara & $1.007,20 \mathrm{~m}$ bar \\
Kecepatan angin & $6 \mathrm{knot}$ \\
Penyinaran matahari & $77 \%$ \\
Curah hujan & $145,29 \mathrm{~mm}$ \\
\hline
\end{tabular}

Sumber : BPS Provinsi NTB 2015

Berdasarkan data BPS Prov NTB tahun 2015 suhu udara tergolong panas yaitu data suhu rata-rata sebesar $32^{\circ} \mathrm{C}$ dan kelembaban udara rata-rata sebesar $78 \%$. Hal ini berpengaruh terhadap kenyamanan dalam beraktivitas pada ruang luar. Curah hujan pada tahun 2015 mengalami peningkatan yang cukup signifikan jika dibandingkan dengan tahun sebelumnya yaitu $145,29 \mathrm{~mm}$. Curah hujan berpengaruh terhadap kekuatan erosi sehingga diperlukan vegetasi yang dapat mencegah erosi.

5. Vegetasi

Berdasarkan hasil pengamatan, vegetasi jenis pohon yang terdapat pada tapak ditampilkan pada Tabel 2.

Tabel 2. Jenis Vegetasi pada Tapak Dasan Cermen

\begin{tabular}{llll}
\hline \multicolumn{1}{c}{ Nama Lokal } & \multicolumn{1}{c}{ Nama Ilmiah } & \multicolumn{1}{c}{ Kondisi Ekologis } & Fungsi Lansekap \\
\hline Bintaro & Cerbera manghas & $\begin{array}{l}\text { Memiliki ukuran sedang yang berada di } \\
\text { pinggir jalan }\end{array}$ & $\begin{array}{l}\text { Sebagai vegetasi } \\
\text { estetik }\end{array}$ \\
Akasia & Acacia longifolia & $\begin{array}{l}\text { Tanaman ini memiliki tutupan vegetasi } \\
\text { jarang dengan ukuran yang sedang. }\end{array}$ & $\begin{array}{l}\text { Sebagai peneduh, } \\
\text { pengarah jalan, } \\
\text { penyepan polutan }\end{array}$ \\
Demara Laut & $\begin{array}{l}\text { Casuarina } \\
\text { equisetifolia L }\end{array}$ & $\begin{array}{l}\text { Tanaman dengan ukuran kecil dengan } \\
\text { bentukan tajuk yang perlu dipangkas } \\
\text { agar terlihat menarik } \\
\text { Sebagai vegetasi } \\
\text { estetik }\end{array}$ & $\begin{array}{l}\text { Memiliki ukuran sedang } \\
\text { Sawit }\end{array}$ \\
Dracaena sp. & Phoenix canariensis & Tanaman ini memiliki ukuran yang kecil vetasi \\
& & & $\begin{array}{l}\text { Sebagai vegetasi } \\
\text { Sebtetik, pengarah } \\
\text { jalan }\end{array}$ \\
\hline
\end{tabular}

6. Aksesibilitas dan Sirkulasi

Tapak terletak di jalan utama Kota Mataram yaitu Jalan Lingkar Selatan dengan lebar jalan sebesar 8 m yang membutuhkan waktu 15 menit dari pusat Kota, 40 menit dari Bandar udara Internasional Lombok serta dari terminal Mandalika dibutuhkan 12 menit.

\section{Sumber Air}

Sumber air pada tapak berasal dari sumur pompa dan air PAM dapat digunakan untuk keperluan pengguna tapak dan air hujan diserap tanah dan dialirkan ke sungai.

8. Fungsi Taman di Kota Mataram

Berdasarkan fungsinya taman di kota Mataram memiliki fungsi menjadi pusat rekreasi dan edukasi (Pemerintah Kota Mataram, 2014).

\subsubsection{Aspek Sosial}

1. Jumlah Penduduk

Lokasi tapak memiliki jumlah penduduk pada tahun 2015 adalah 4.355 jiwa sedangkan di Kota Mataram pada Tahun 2015 sebesar 450.226 jiwa (Pengelola Informasi dan Dokumentasi,2015). 


\section{Pengguna Taman di Kota Mataram}

Pengguna taman di Kota Mataram didominasi 80\% masyarakat Kota Mataram dan sisanya masyarakat luar Kota Mataram. Pengguna taman laki-laki (53\%) lebih sering datang dibanding wanita (46\%) dengan usia dari 13 tahun hingga 40 tahun.

\subsection{Analisis dan Sintesis}

Tahap analisis dan sintesis merupakan tahap mengolah data yang didapatkan pada tahap inventarisasi sehingga mengetahui potensi dan masalah yang ada.

\subsubsection{Aspek Biofisik}

1. Letak dan Luas Lahan

Lokasi tapak secara fisik pada sebelah utara dibatasi oleh lahan penduduk berupa area dengan tanaman tegakan tinggi dan persawahan, serta berbatasan dengan SMKN 7 Mataram di sebelah timur dan sebelah barat dibatasi oleh perumahan penduduk dan SDN 46 Ampenan serta sebelah selatan berbatasan dengan Sungai Unus. Pemukiman penduduk yang cukup padat mengakibatkan kurangnya ruang bersosialisasi bagi masyarakat menjadi salah satu potensi tapak dijadikan RTP. Sungai Unus membutuhkan sempadan sungai agar tidak membahayakan bagi pengguna RTP. Adapun beberapa vegetasi yang dapat digunakan pada RTH sempadan sungai dapat dilihat pada Tabel 3.

Tabel 3. Alternatif Vegetasi pada RTH Sempadan Sungai

\begin{tabular}{ll}
\hline Nama Lokal & Nama Ilmiah \\
\hline Beringin & Ficus Benjamin \\
Jamplung & Callophylum inophyllum \\
Kenanga & Canangium odoratum \\
Flamboyan & Delonix regia \\
Trembesi & Samanea saman \\
\hline Sumber: Peraturan Menteri Pekerjaan Umum Nomor 5 Tahun 2008
\end{tabular}

\section{Topografi}

Berdasarkan BPS Kecamatan Cakranegara (2016), pada tapak memiliki topografi datar sehingga memudahkan dalam mengolah tapak. Menurut Booth (1983) dalam Veggyana (2016) mengemukakan, tapak datar adalah tapak yang dapat dikembangkan secara maksimal. Sedangkan menurut Hakim dan Utomo (2002) kelemahan tapak datar adalah visual yang terlalu monoton, sehingga diperlukan aksen yang menarik untuk menghilangkan kesan monoton pada tapak.

\section{Kondisi Tanah}

Tapak yang direncanakan memiliki jenis tanah aluvial. Menurut Sunarko (2014) karakteristik tanah ini cukup potensial dalam pertumbuhan dan perkembangan semua jenis vegetasi dan memudahkan pembangunan fasilitas taman.

4. Iklim

Berdasarkan data BPS Provinsi NTB Tahun 2015, indeks kelembaban termal (THI) pada tapak masuk ke dalam kategori tidak nyaman yaitu sebesar 30,5. Menurut Talaila et al. (2013), suatu area dikatakan nyaman jika memiliki nilai THI 20-26. Sehingga perlu modifikasi iklim mikro agar dapat dikategorikan nyaman. Salah satunya dengan menambahkan vegetasi peneduh. Iswanto (2006) berpendapat bahwa vegetasi sebagai pengendali iklim untuk kenyamanan manusia sehingga menurunkan suhu dan iklim mikro.

5. Vegetasi

Menurut Hakim dan Utomo (2002) vegetasi memiliki beberapa fungsi. Analisis fungsi vegetasi berdasarkan hasil inventarisasi pada tapak dapat dilihat pada Tabel 4. 
Tabel 4. Analisis Fungsi Vegetasi

\begin{tabular}{|c|c|c|}
\hline Fungsi Vegetasi & Analisis & Sintesis \\
\hline Pembatas & $\begin{array}{l}\text { Belum ada vegetasi pada tapak yang } \\
\text { memiliki fungsi tersebut. }\end{array}$ & $\begin{array}{l}\text { Menambahkan vegetasi yang } \\
\text { diperlukan seperti kukin. }\end{array}$ \\
\hline Penyerap polutan & $\begin{array}{l}\text { Tanaman akasia pada tapak telah memenuhi } \\
\text { akan tetapi serbuk sari pada akasia } \\
\text { menyebabkan alergi(Rengganis, 2009). }\end{array}$ & $\begin{array}{l}\text { Mengganti tanaman akasia dengan } \\
\text { tanaman lainnya seperti jamplung. }\end{array}$ \\
\hline Pencegah Erosi & $\begin{array}{l}\text { Belum ada vegetasi pada tapak yang } \\
\text { memiliki fungsi tersebut. }\end{array}$ & $\begin{array}{l}\text { Menambahkan vegetasi yang } \\
\text { diperlukan yaitu vegetasi penahan air } \\
\text { yang jatuh kepermukaan tanah dan } \\
\text { daya serap air yang tinggi serta } \\
\text { memiliki akar yang kuat seperti } \\
\text { kelicung. }\end{array}$ \\
\hline Habitat Satwa & $\begin{array}{l}\text { Belum ada vegetasi pada tapak yang } \\
\text { memiliki fungsi tersebut. }\end{array}$ & $\begin{array}{l}\text { Menambahkan vegetasi yang } \\
\text { diperlukan yaitu vegetasi } \\
\text { pengundang satwa seperti tanaman } \\
\text { ketimus atau loa. }\end{array}$ \\
\hline Nilai Estetis & $\begin{array}{l}\text { Tanaman cemara, bintaro dan sawit belum } \\
\text { memenuhi kriteria. }\end{array}$ & $\begin{array}{l}\text { Mengganti dengan tanaman lainnya } \\
\text { seperti sentul. }\end{array}$ \\
\hline
\end{tabular}

6. Aksesibilitas dan Sirkulasi

Lokasi tapak berada di jalur utama Kota Mataram sehingga menjadi potensi memudahkan pengguna taman dalam mengakses tapak. Pengunjung tapak yang menggunakan kendaraan diarahkan menuju areal parkir. Areal parkir dibagi menjadi dua yaitu areal di sebelah barat dan areal parkir sebelah timur. Pejalan kaki dapat menggunakan pedestrian yang menuju tapak dengan ukuran 2 meter. Kendala pada tapak yaitu dengan adanya RTP akan menimbulkan ketidaknyamanan penduduk sekitar tapak karena dapat menyebabkan kepadatan kendaraan. Solusi dari kendala tersebut dengan menciptakan dua arah sirkulasi keluar masuk kendaraan dan memperlebar jalan pada tapak sehingga mengurangi resiko kepadatan pada satu jalur kendaraan.

\section{Sumber Air}

Kecamatan Cakranegara sudah memiliki beberapa sumber air bersih sehingga dalam memenuhi kebutuhan air untuk sarana taman dapat terpenuhi. Saluran drainase pada tapak masih berupa selokan dari tanah sehingga saluran ini ditumbuhi oleh tanaman liar karena itu drainase perlu diperjelas dengan penambahan beton agar perawatannya lebih mudah dan aliran air lebih terarah.

\subsubsection{Aspek Sosial}

1. Jumlah Penduduk

Berdasarkan data BPS Kota Mataram, jumlah penduduk Kota Mataram Tahun 2015 sebesar 450.226 jiwa sehingga diperlukan adanya penyediaan RTP berupa taman kecamatan. Menurut Peraturan Menteri Pekerjaan Umum Nomor 5 Tahun 2008, taman kecamatan mengakomodasi penduduk di suatu wilayah minimal sebesar 120.000 jiwa.

2. Pengguna Taman di Kota Mataram

Untuk mengetahui karakter pengguna dan kesesuaian budaya lokal pada tapak, dilakukan akumulasi hasil kuesioner seperti pada Tabel 5 dan Tabel 6 . Analisis didasarkan pada pertanyaan mengenai karakteristik pengunjung taman, fasilitas yang diharapkan dan saran terhadap pengembangan budaya di taman.

Tabel 5 Analisis Karakter Pengunjung Taman Kota Mataram

\begin{tabular}{|c|c|c|c|}
\hline No & $\begin{array}{c}\text { Karakter } \\
\text { pengunjung }\end{array}$ & Analisis & Sintesis \\
\hline 1 & $\begin{array}{l}\text { Jenis } \\
\text { Berkunjung }\end{array}$ & $\begin{array}{l}65 \% \text { berkelompok, } \\
28 \% \text { berdua, } \\
7 \% \text { sendiri. }\end{array}$ & $\begin{array}{l}\text { Pengunjung membutuhkan area yang dapat mewadahi aktivitas } \\
\text { berkelompok seperti memberikan gazebo, lapang berumput } \\
\text { dengan vegetasi peneduh yang dapat menampung pengunjung } \\
\text { untuk berkumpul serta food court dan toilet untuk memenuhi } \\
\text { kebutuhan fasilitas pengunjung. }\end{array}$ \\
\hline 2 & $\begin{array}{l}\text { Waktu } \\
\text { berkunjung }\end{array}$ & $\begin{array}{l}76 \% \text { sore hari, } \\
14 \% \text { pagi hari, }\end{array}$ & $\begin{array}{l}\text { Dominan waktu berkunjung pada sore hari dikarenakan memiliki } \\
\text { kesejukan yang memberikan kenyamanan pada pengunjung }\end{array}$ \\
\hline
\end{tabular}


Lanjutan tabel 5

\begin{tabular}{|c|c|c|c|c|c|c|}
\hline No & $\begin{array}{c}\text { Karakter } \\
\text { pengunjung }\end{array}$ & & Analisis & \multicolumn{3}{|c|}{ Sintesis } \\
\hline & & \multicolumn{2}{|c|}{$\begin{array}{l}\text { 7\% malam hari, } \\
3 \% \text { siang hari. }\end{array}$} & \multicolumn{3}{|c|}{$\begin{array}{l}\text { sehingga dibutuhkan vegetasi peneduh untuk kesejukan pada } \\
\text { siang hari. Selain itu, terdapat kendala yaitu pengunjung jarang } \\
\text { datang pada malam hari yaitu karena tidak adanya penerangan, } \\
\text { dibutuhkan lampu penerangan pada taman }\end{array}$} \\
\hline 3 & $\begin{array}{l}\text { Lama } \\
\text { Berkunjung }\end{array}$ & \multicolumn{2}{|c|}{$\begin{array}{l}52 \% 1-2 \text { jam, } \\
38 \%<1 \text { jam, } \\
10 \% 3-5 \text { jam. }\end{array}$} & \multicolumn{3}{|c|}{$\begin{array}{l}\text { Pengunjung dominan berkunjung sekitar satu hingga dua jam } \\
\text { sebab pengunjung datang pada sore hari mulai dari jam } 16.00 \text { - } \\
18.00 \text { sehingga diperlukan ruang yang dapat mewadahi } \\
\text { pengunjung dalam melakukan aktivitas rekreasi seperti bermain } \\
\text { dan bersantai serta aktivitas olahraga. }\end{array}$} \\
\hline 4 & $\begin{array}{l}\text { Cara } \\
\text { mencapai } \\
\text { lokasi }\end{array}$ & \multirow{3}{*}{\multicolumn{2}{|c|}{$\begin{array}{l}67 \% \text { motor/mobil, } \\
22 \% \text { sepeda, } \\
7 \% \text { pejalan kaki, } \\
4 \% \text { angkutan } \\
\text { umum } \\
58 \% \text { lapangan } \\
\text { berumput, } \\
38 \% \text { Panggung } \\
\text { terbuka, } \\
4 \% \text { bangku taman. }\end{array}$}} & \multirow{3}{*}{\multicolumn{3}{|c|}{$\begin{array}{l}\text { Banyaknya pengunjung yang membawa kendaraan pribadi, } \\
\text { sehingga dibutuhkan areal parkir kendaraan. Pengunjung yang } \\
\text { tinggal dekat dengan tapak, pengunjung bisa berjalan kaki } \\
\text { sehingga dibutuhkan adanya jalur pedestrian untuk memberikan } \\
\text { keamanan dan kenyamanan bagi para pejalan kaki. } \\
\text { Fasilitas penunjang kegiatan budaya yang dibutuhkan yaitu area } \\
\text { lapang sebagai areal yang digunakan dalam kegiatan budaya } \\
\text { Peresean, sedangkan panggung terbuka menjadi area untuk } \\
\text { melakukan kegiatan budaya begasingan maupun festival } \\
\text { budaya. Sedangkan bangku taman tidak memiliki fungsi yang } \\
\text { menunjang kegiatan budaya disebabkan karena kegiatan } \\
\text { budaya menarik banyak orang di dalamnya untuk berkontribusi } \\
\text { atau menjadi penonton. }\end{array}$}} \\
\hline \multicolumn{2}{|c|}{ Lanjutan tabel 6} & & & & & \\
\hline 5 & $\begin{array}{l}\text { Fasilitas } \\
\text { penunjang } \\
\text { kegiatan } \\
\text { budaya }\end{array}$ & & & & & \\
\hline \multicolumn{7}{|c|}{ Tabel 6. Analisis Kegiatan Budaya Lokal } \\
\hline No & \multicolumn{2}{|c|}{ Kegiatan budaya } & \multicolumn{2}{|c|}{ Aktivitas } & Kebutuhan Ruang & $\begin{array}{c}\text { Kebutuhan } \\
\text { Fasilitas }\end{array}$ \\
\hline 1 & Peresean & \multicolumn{3}{|c|}{$\begin{array}{l}\text { Atraksi perang, atraksi iringan } \\
\text { musik, lokasi penonton, } \\
\text { enyembuhkan luka, durasi tiga } \\
\text { jam. }\end{array}$} & $\begin{array}{l}\text { Area terbuka minimal } 10 \\
\times 10 \mathrm{~m}^{2} \text {, area iringan } \\
\text { musik dan area P3K. }\end{array}$ & $\begin{array}{l}\text { Area terbuka } \\
\text { dengan } \\
\text { beralasan } \\
\text { tanah maupun } \\
\text { rumput dan } \\
\text { ruang ganti. }\end{array}$ \\
\hline 2 & Begasingan & \multicolumn{3}{|c|}{$\begin{array}{l}\text { Parade budaya, atraksi } \\
\text { bermain gasing, durasi tiga } \\
\text { jam. }\end{array}$} & $\begin{array}{l}\text { Area terbuka dan area } \\
\text { persiapan parade. }\end{array}$ & $\begin{array}{l}\text { Area terbuka } \\
\text { dengan } \\
\text { beralasan lantai } \\
\text { beton, } \\
\text { panggung } \\
\text { terbuka dan } \\
\text { ruang ganti }\end{array}$ \\
\hline
\end{tabular}

\subsection{Konsep Dasar}

Lokasi berada dekat dengan sekolah dapat menjadi wadah aktivitas siswa yang membutuhkan ruang terbuka yang luas seperti aktivitas olahraga maupun ekstrakulikuler sekolah. Adanya Taman juga berfungsi sebagai ruang interaksi sosial bagi masyarakat. Sungai merupakan batas selatan tapak dan memerlukan ruang untuk pelestarian sungai sebagai pencegah erosi dan kawasan konservasi. Budaya lokal seperti peresean dan begasingan membutuhkan ruang berekspresi sebagai identitas masyarakat lokal Kota Mataram. Konsep dasar memuat perpaduan antara ruang ekspresi budaya masyarakat pada taman dan konservasi sungai. Oleh karena itu, diperlukan adanya zona bagi atraksi budaya lokal, zona sosial untuk masyarakat berkumpul dan zona konservasi untuk melestarikan badan sungai. Berdasarkan kondisi tersebut maka konsep dasar yang diterapkan pada tapak adalah pelestarian budaya lokal.

\subsection{Konsep Pengembangan}

Berdasarkan data yang didapat dan diolah pada tahap analisis dan sintesis, cerminan konsep dasar terlihat pada konsep ruang, sirkulasi dan vegetasi yang dapat mendukung berbagai aktivitas sosial bagi para pengguna taman, konservasi sungai dan dapat menampung kegiatan budaya lokal. 


\subsubsection{Konsep Ruang}

Konsep ruang pada taman adalah sebagai wadah aktivitas sosial dan aktivitas budaya masyarakat Kota Mataram serta pelestarian sungai. Aktivitas sosial masyarakat berupa interaksi sosial dan aktivitas budaya masyarakat lokal yaitu peresean dan begasingan. Pelestarian sungai berupa konservasi bantaran sungai.

\subsubsection{Konsep Sirkulasi}

Konsep sirkulasi dibuat untuk menghubungkan seluruh masyarakat untuk mempermudah aktivitas antar ruang maupun aktivitas di dalam ruang. Pola sirkulasi yang digunakan yaitu pola sirkulasi linear yang terlihat pada jalur kendaraan dan campuran terlihat di dalam tapak.

\subsubsection{Konsep Vegetasi}

Konsep vegetasi pada perencanaan ini adalah pemanfaatan vegetasi lokal daerah Nusa Tenggara Barat dapat dilihat pada Tabel 7.

Tabel 7. Referensi Vegetasi Lokal

\begin{tabular}{|c|c|c|c|}
\hline No & Nama Lokal & Nama Ilmiah & Keterangan \\
\hline 1 & Kelicung & $\begin{array}{l}\text { Garcinia } \\
\text { dulcis }\end{array}$ & $\begin{array}{l}\text { Tinggi mencapai 10- } 46 \text { meter, diameter batang } 60 \mathrm{~cm} \text {, mampu } \\
\text { hidup hingga ketinggian } 800 \mathrm{~m} \text { dpl, dapat hidup di daerah basar } \\
\text { seperti tepi sungai, memiliki bunga yang harum dan berwarna putih } \\
\text { kekuningan. }\end{array}$ \\
\hline 2 & Sentul & $\begin{array}{l}\text { Sandoricum } \\
\text { koetjape }\end{array}$ & $\begin{array}{l}\text { Tinggi mencapai } 30 \text { meter, diameter batang } 90 \mathrm{~cm} \text {, mampu hidup } \\
\text { hingga ketinggian } 1000 \mathrm{~m} \text { dpl, dapat hidup di daerah yang curah } \\
\text { hujan sedang, memiliki bunga berbau harum dan buah yang dapat di } \\
\text { makan. }\end{array}$ \\
\hline 3 & Jamplung & $\begin{array}{l}\text { Callophylum } \\
\text { inophyllum }\end{array}$ & $\begin{array}{l}\text { Tinggi mencapai } 20 \text { meter, diameter batang } 150 \mathrm{~cm} \text {, mampu hidup } \\
\text { hingga ketinggian } 350 \mathrm{~m} \text { dpl, dapat hidup di daerah basah } \\
\text { danberiklim kering seperti pantai dan tepi sungai dan memiliki buah } \\
\text { yang dapat dijadikan bahan utama pembuatan gasing }\end{array}$ \\
\hline 4 & $\begin{array}{l}\text { Ketimus/ } \\
\text { Loa }\end{array}$ & $\begin{array}{l}\text { Protium } \\
\text { javanicum }\end{array}$ & $\begin{array}{l}\text { Tinggi mencapai 15- } 25 \text { meter, diameter batang } 75 \mathrm{~cm} \text {, mampu } \\
\text { hidup pada ketinggian hingga } 251 \mathrm{~m} \text { dpl, dapat hidup didataran } \\
\text { rendah, biasanya hidup di pinggir sungai, memiliki buah yang dapat } \\
\text { dimakan. }\end{array}$ \\
\hline 5 & Kukin & $\begin{array}{l}\text { Schoutenia } \\
\text { ovate }\end{array}$ & $\begin{array}{l}\text { Tinggi mencapai } 25 \text { meter, diameter batang } 40-45 \mathrm{~cm} \text {, mampu } \\
\text { hidup hingga ketinggian } 900 \mathrm{~m} \text { dpl, dapat hidup didataran rendah } \\
\text { dengan lahan yang basah maupun berkapur, memiliki bunga } \\
\text { berwarna putih kekuningan dengan buah kecil. }\end{array}$ \\
\hline
\end{tabular}

Sumber: Wahyuni dan Mildranaya (2010)

\subsection{Perencanaan}

Perencanaan tapak didasarkan pada konsep pengembangan yang telah dilakukan dengan menghasilkan tata ruang (Gambar 1), tata sirkulasi (Gambar 2) dan tata hijau (Gambar 3 dan Gambar 4). Sedangkan produk yang dihasilkan berupa site plan (Gambar 5 dan Gambar 6) yaitu gambar akhir dari konsep pengembangan.

Berdasarkan fungsinya, penataan ruang dibagi menjadi tiga yaitu ruang konservasi, ruang sosial dan ruang budaya. Ruang konservasi merupakan RTH yang berada di bagian taman sebelah selatan yang berfungsi sebagai pencegah erosi karena terdapat sungai sebagai batasan tapak. Ruang sosial adalah ruang yang digunakan untuk aktivitas sosial berupa aktivitas berinteraksi sosial, pada ruang ini terdapat area rekreasi, amphitheater, area olahraga, area parkir, foodcourt, toilet dan gazebo. Ruang budaya adalah ruang yang digunakan dalam mendukung aktivitas budaya lokal yaitu peresean dan begasingan. Pada ruang ini terdapat area festival dan toilet.

Tata sirkulasi dibuat berdasarkan hubungan antar ruang yang dimanfaatkan untuk memudahkan pengunjung berpindah dari satu tempat ke tempat lainnya. Pada tapak ini terdapat dua jenis sirkulasi, yaitu sirkulasi kendaraan dan sirkulasi pejalan kaki. Sirkulasi kendaraan dimulai dari Jalan Lingkar Selatan kemudian memasuki jalan perumahan warga, selanjutnya memasuki area parkir. Akses keluar dari tapak yaitu melalui Jalan Lingkar Selatan atau dapat melalui Jalan Teguh Lopan. Sirkulasi di buat dengan dua jalur agar 
mengurangi penumpukan kendaraan dari dua arah keluar masuk tapak. Sirkulasi pejalan kaki sendiri memiliki variasi ukuran yaitu mulai dari 1,25 meter hingga 3 meter.

Tata hijau menggunakan konsep vegetasi lokal Kota Mataram. Dalam pengembangannya, tata hijau dibagi dalam beberapa kategori fungsi yaitu peneduh, pembatas, penyerap polutan, pencegah erosi dan nilai estetis. Penempatan vegetasi berdasar fungsinya dapat dilihat pada Tabel 8.

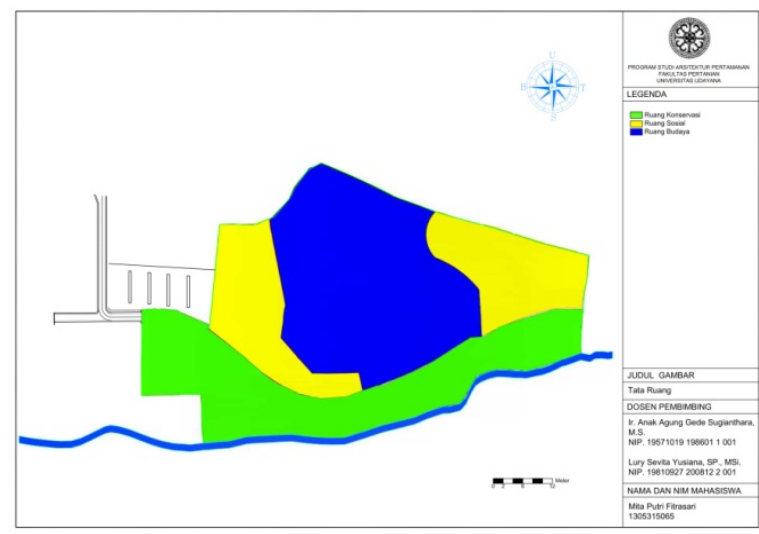

Gambar 1. Tata Ruang
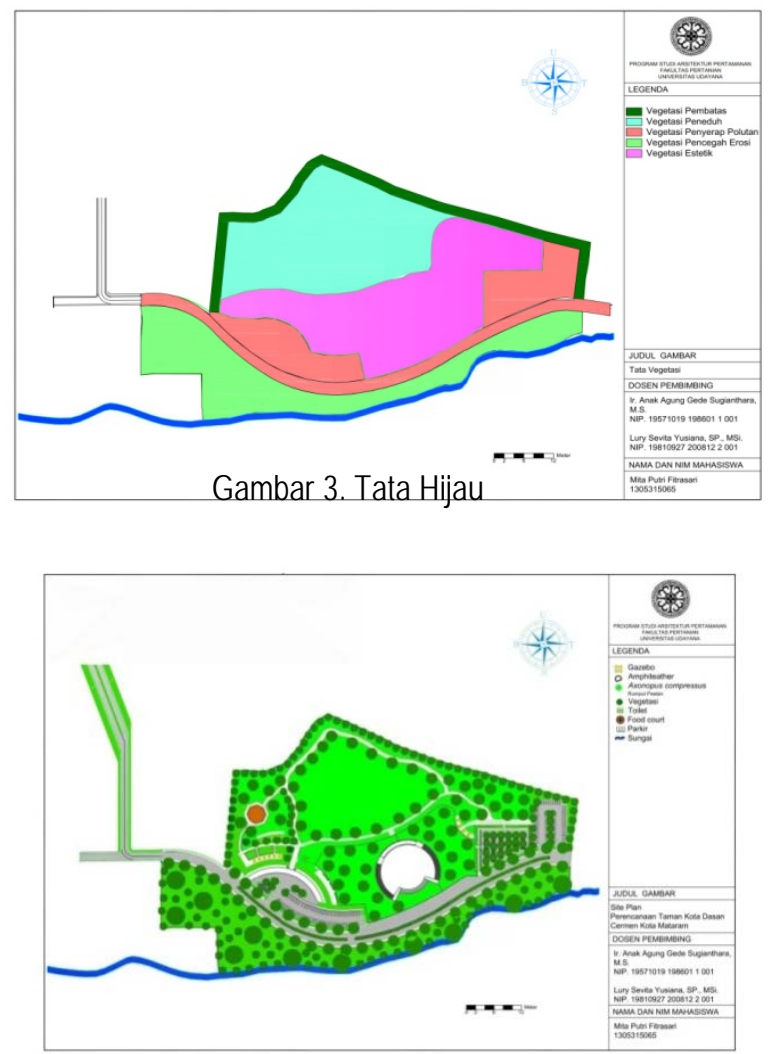

Gambar 5. Site Plan

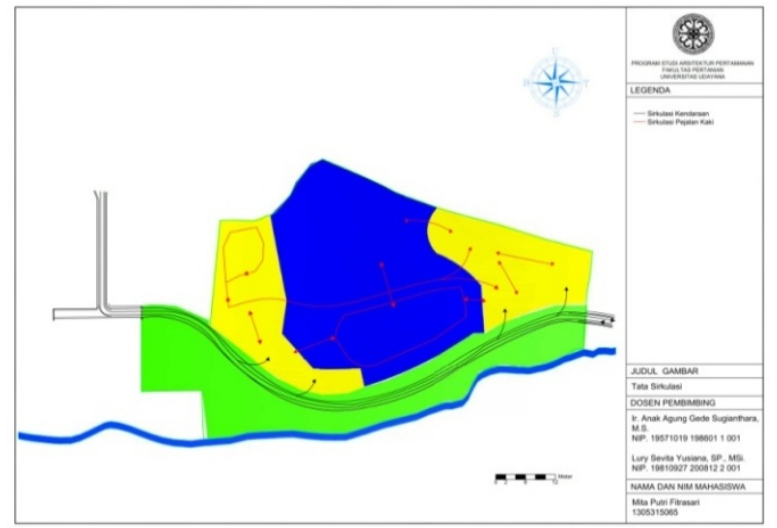

Gambar 2. Tata Sirkulasi
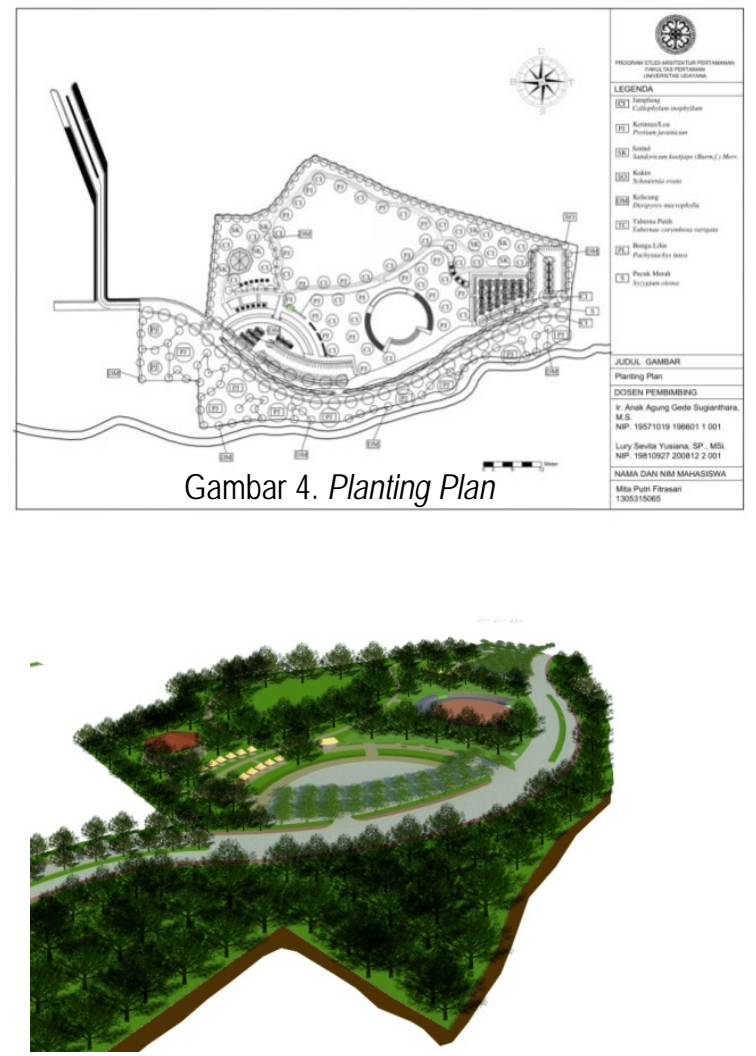

Gambar 6. Ilustrasi Site Plan 
Tabel 8 Tata Hijau Berdasarkan Fungsinya

\begin{tabular}{lll}
\hline Ruang & Fungsi Vegetasi & Jenis Vegetasi \\
\hline Sosial & Vegetasi peneduh & Ketimus / Loa (Protium javanicum) \\
& & Kelicung (Garcinia dulcis) \\
& Vegetasi pembatas & Kukin (Schoutenia ovata) \\
& Vegetasi estetik & Kukin (Schoutenia ovata) \\
& & Jamplung (Callophylum inophyllum) \\
& & Sentul (Sandoricum koetjape) \\
Budaya & Vegetasi peneduh & Jamplung (Callophylum inophyllum) \\
Lanjutan Tabel 9 & Vegetasi pembatas & Kukin (Schoutenia ovata) \\
Konservasi & Vegetasi pencegah erosi & Ketimus / Loa (Protium javanicum) \\
& & Kelicung (Garcinia dulcis) \\
& Vegetasi penyerap polutan & Jamplung (Callophylum inophyllum) \\
& & Pucuk Merah (Syzygium oleina) \\
& & Bunga Lilin (Pachystachys lutea) \\
& & Taberna Putih (Tabernae corymbosa varigata) \\
\hline
\end{tabular}

\section{Simpulan}

Ruang terbuka publik diperlukan masyarakat lokal Kota Mataram untuk mengekspresikan budaya lokal berupa budaya peresean dan begasingan. Ruang terbuka publik direncanakan sebagai Taman Dasan Cermen yang mampu mengakomodir fungsi tersebut. Selain itu, Taman Dasan Cermen juga memiliki fungsi sosial dan fungsi ekologi. Fungsi sosial sebagai tempat rekreasi diwujudkan dalam ruang sosial. Fungsi ekologi berupa pencegah erosi dan pelestarian vegetasi lokal yang diwujudkan pada ruang konservasi.

Perencanaan RTP Dasan Cermen memiliki konsep dasar yaitu pelestarian budaya lokal. Penerapan konsep pelestarian budaya didasari oleh aktivitas masyarakat lokal yang berada di RTP dalam menggambarkan ekspresi budaya. Konsep ruang yang digunakan mengacu pada konsep dasar yaitu sebagai wadah aktivitas sosial budaya masyarakat Kota Mataram dan sebagai ruang pelestarian sungai. Pembagian ruang pada Taman Dasan Cermen dibagi menjadi tiga ruang antara lain, ruang sosial, ruang budaya dan ruang konservasi. Ruang sosial sebagai ruang untuk pengunjung berinteraksi sosial di taman, ruang budaya digunakan untuk mendukung aktivitas kesenian budaya lokal dan ruang konservasi yaitu sebagai kawasan pelestarian vegetasi lokal. Penggunaan vegetasi lokal sebagai cerminan identitas budaya lokal merupakan konsep vegetasi yang didasari oleh konsep dasar yaitu pelestarian budaya lokal. Konsep sirkulasi dibuat untuk menghubungkan seluruh masyarakat dalam mempermudah aktivitas antar ruang maupun aktivitas di dalam ruang. Perencanaan taman Dasan Cermen Kota Mataram merupakan perwujudan dari konsep pengembangan dengan hasil berupa site plan dan ilustrasi perencanaan RTP sebagai Taman Dasan Cermen di Kota Mataram.

\section{Daftar Pustaka}

BPS Kecamatan Cakranegara. 2016. Statistik Daerah Kecamatan Cakranegara 2016. Badan Pusat Statistik: Mataram

BPS Kota Mataram. 2015. Mataram Dalam Angka 2015. Badan Pusat Statistik: Mataram

BPS Provinsi Nusa Tenggara Barat. 2015. Statistik Provinsi Nusa Tenggara Barat 2015. Badan Pusat Statistik: Mataram

Hakim, R. dan Utomo, H. 2002. Komponen Perancangan Arsitektur Lansekap. Bumi Aksara: Jakarta.

Iswanto, Danoe. 2006. Kajian Ruang Publik ditinjau dari Segi Proporsi / Skala dan Enclosure. Jurnal IImiah Perencanaan Kota dan Pemukiman, 5(2):74-81.

Kementerian Pekerjaan Umum. 2008. Pedoman Penyediaan dan Pemanfaatan Ruang Terbuka Hijau DI Kawasan Perkotaan. Direktorat Jendral Penataan Ruang Departemen Pekerjaan Umum: Jakarta.

Pejabat Pengelola Informasi dan Dokumentasi Kota Mataram. 2015. Gambaran Umum kelurahan Dasan Cermen. Pejabat Pengelola Informasi dan Dokumentasi: Mataram.

Pemerintah Kota Mataram. 2011. Rencana Penataan Ruang Terbuka Hijau (RTH) Kota Mataram. Pemerintah Kota Mataram: Mataram.

Pemerintah Kota Mataram. 2014. Wisata Taman di Kota Mataram. http://mataramkota.go.id/wisata-tamankota-2.html. Diakses pada 3 April 2017

Sunarko. 2014. Budi Daya Kelapa Sawit di Berbagai Jenis Lahan. PT AgroMedia Pustaka: Jakarta. 
Talaila, M., Meles, B. and Tiexeira, L. 2013. Evaluation of the Thermal Comfort in Workplaces-a study in the Metalworking Industry. Occupational Safety and Hygiene. Editor Arezes et al. Taylor \& Francis Group: London.

Veggyana, V. 2016. Desain Lanskap Pasar Seni Arifin Ahmad Sebagai Objek Wisata Kuliner Kota Pekanbaru. Skripsi (tidak dipublikasikan) Institut Pertanian Bogor: Bogor.

Wahyuni, T. E. dan Mildranaya, E. 2010. Panduan Wisata Alam Di Kawasan Konsrvasi Nusa Tenggara Barat. Balai Konservasi Sumber Daya Alam NTB: Mataram. 